\title{
Online spiral grade control
}

\author{
A.M. Russell ${ }^{1}$
}

Affiliation:

${ }^{1}$ Mintek, Randburg, South Africa.

Correspondence to:

D. Phillpotts

Email:

davidph@mintek.co.za

Dates:

Received: 22 Aug. 2019

Revised: 17 Dec. 2019

Accepted: 14 Jan. 2020

Published: February 2020

How to cite:

Russell, A.M.

Online spiral grade control.

The Southern African Insitute of

Mining and Metallurgy

DOI ID:

http://dx.doi.org/10.17159/24119717/892/2020

This paper was first presented at The Eleventh International Heavy Minerals Conference, 5-6 August 2019, The Vineyard, Cape Town, South Africa.

\section{Synopsis}

Online control of gravity spiral concentrators has not been widely implemented, despite the scale of industrial spiral circuits and the associated labour requirements of manually adjusting the spiral splitter positions to counter disturbances. Previous industrial and academic attempts at automation initially showed some promising results, but have thus far not resulted in the implementation of large-scale control system at industrial sites. A new technique making use of jets of process water for the control of spiral product quality is proposed, and which is suitable for retrofitting to existing spiral circuits. A test programme carried out at a chromite plant processing UG2 flotation tailing at a site on the eastern limb of the Bushveld Complex in South Africa showed that online control of the spiral plant concentrate grade using this technique is feasible.

\section{Keywords}

spiral concentrator, optimization, online control, grade-recovery tradeoff.

\section{Introduction}

Gravity spiral separators are widely utilized for the physical separation of a number of ore types. In the South African context, gravity spirals are used extensively in the concentration of chromite, coal, and mineral sands. While the process flow sheets and operating conditions vary widely between these industries, the nature of the spirals used across different sectors is similar.

The most common types of spirals consist of a trough that twists downward in a helix (typically clockwise) about a central axis. A slurry mixture is fed to the top of the spiral from a distributor. As the material travels down the length of the spiral, a combination of gravity and hydrodynamic forces (Mishra and Tripathy, 2010) results in the lighter material being lifted and carried to the outer portion of the spiral while the heavier material remains on the inner portion of the spiral (Matthews, Fletcher, and Partridge, 1999). The disproportionate movement of heavy and light minerals results in the formation of regions of increased concentrations of heavy and light minerals.

In some designs, auxiliary splitters along the length of the trough allow heavy material at intermediate points down the spiral to be removed and sent directly to a product stream, thereby freeing processing capacity on the lower part of the spiral. An adjustable product splitter is installed at the base of the spiral, typically with two or three splitter blades. The relative positions of these splitter blades determine the proportions of the separated material that will report to the individual product streams.

The relative positions of the product splitter blades at the base of the spiral, as well as the positions of the auxiliary splitters along the length of the spiral, are manually adjusted. Since spiral concentrator plants typically make use of vast numbers of spirals comprising different processing stages, the manual adjustment of these splitters to counter fluctuations in plant operating conditions is time-consuming and impractical (Vermaak et al., 2008). To ensure that product grades are maintained within specifications, the splitters are often positioned conservatively, thus resulting in mineral losses.

\section{Background}

There have been a number of attempts at implementing online measurement and control on spiral separators and related equipment such as shaking tables. A number of investigations have involved the use of the visual appearance of materials as a proxy for product quality or separation effectiveness, in many ways mimicking the measurements made by the operators on processing plants.

A patent application by Welsh and Deurbrouck (1973), details the use of a photoelectric sensor coupled with a mechanical sorting device to optimize the recovery of valuable material on a shaking 


\section{Online spiral grade control}

table. An investigation by Gold (1991) sought to develop an algorithm to detect the interface position between mineral bands on a spiral. Recently, Nienaber, McCoy, and Auret (2017) used a statistical learning approach to improve the reliability of mineral band detection. High detection success rates were achieved in the case of ilmenite interfaces; however, much lower success rates were achieved on chromite samples.

A model of the relationship between the mineral band position and spiral feed properties such as flow rate, grade, solids composition, and viscosity was developed by Vermaak et al. (2008) for material with a low slimes content. The model was also used to predict the mineral band position for a sample where the mineral band interface cannot be optically detected due to the presence of slimes. Such a model would be useful for process control purposes; however, the necessary measurements are not available on most spiral concentrator plants.

The use of inflatable bladders to divert material on a spiral surface to the desired product port is described in a European patent by Cooke (2009). Similarly, the work by Thornton and Carnell (2018) details the use of pneumatically actuated splitters mounted above a spiral trough to influence the proportion of material flowing to the product and reject ports. In that work, plans to incorporate this actuation mechanism with online density measurements are mentioned, but no online control results are provided.

The use of solids density gradients (based on electrical conductivity measurements) to inform the mechanical manipulation of the product splitters was detailed by Mohanty, Wang, and Zhang (2014).

The limited investigations into spiral control have so far not resulted in feasible, long-term industrial implementations, despite promising results under laboratory conditions or pilotscale industrial conditions. It is believed that this is mainly due to the complexity and cost involved in scaling a control system from the laboratory scale to an industrial scale. Furthermore, the cost and challenges associated with the maintenance of a complicated control system conflict with the relatively low capital and maintenance costs associated with gravity spirals, further deterring operational management from applying such a control system to a spiral circuit.

\section{Engineering design}

\section{Spiral actuation using spray nozzles}

A number of previous attempts have sought to manipulate the mass flows of material to the different product ports on a spiral by moving the installed product and/or auxiliary splitters using mechanical devices. While moving the product splitter in this way emulates the manual process of moving the splitter, a number of practicalities have to be considered.

> Each mechanical actuator requires the supply of utilities, including instrument air and electrical power.

- Spiral plant conditions are quite harsh, with large amounts of fine material present. In some cases salt water is used as a process medium, exacerbating corrosion. The maintenance requirements for a large installation of mechanical actuators would be a significant burden for many plants.

- Mechanical actuators require robust mounting points about which to act, a rarity on spiral plants.

> The cost of fitting mechanical actuators to a bank of spirals will be beyond the reach of many operating plants.

A novel actuation system that makes use of multiple spray nozzles creating jets of process water to manipulate the flow of material on a bank of spirals has been developed and patented. The mode of action of the spray nozzles is illustrated in Figures 1 and Figure 2.

The mode of action of the spray nozzles is as follows.

> Nozzles are statically mounted in an optimal position above each of the concentrate and gangue material regions on the spiral, upstream from either a product or auxiliary splitter.

- The impact of the water on the spiral surface creates a blast zone that is triangular in shape with a stationary apex. The location of this zone determines the point from which material will be shifted.

- The pressure of the water feeding the spray nozzles is manipulated to alter the width of the blast zone, and hence the degree to which material is pushed towards the alternative product port.

- The overall effect is such that the blast zone alters the
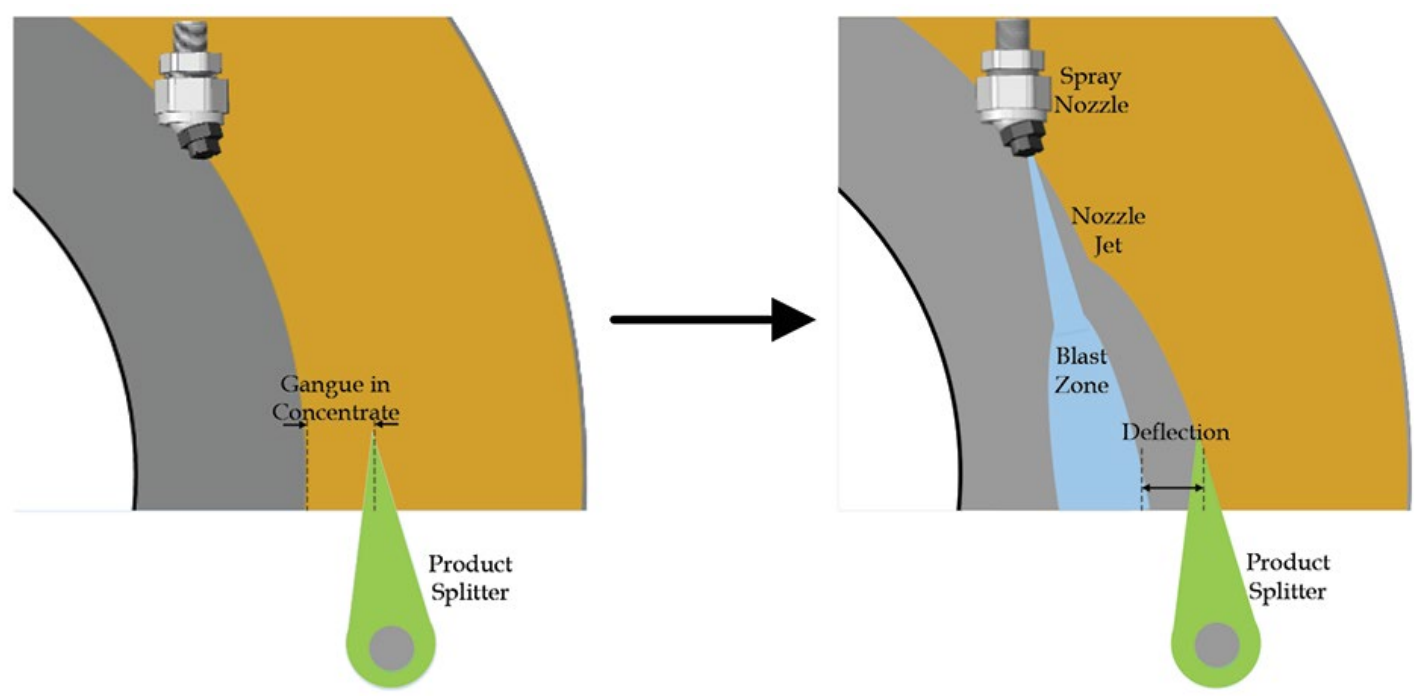


\section{Online spiral grade control}
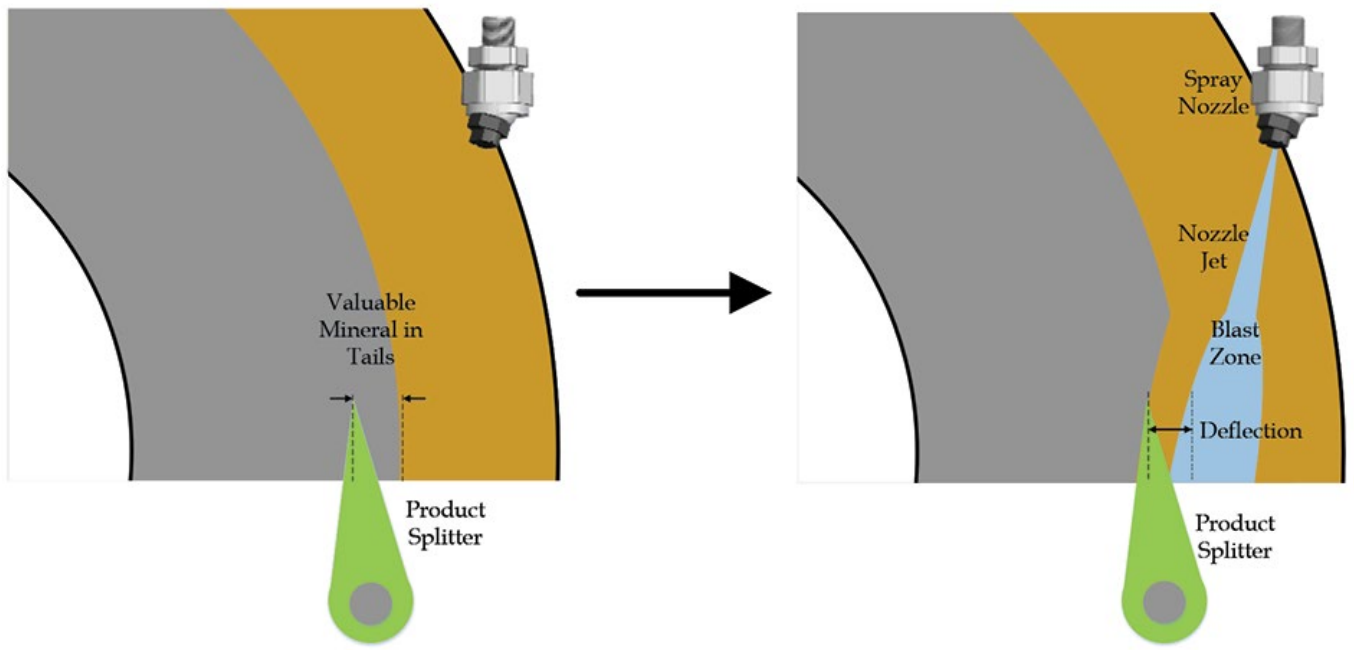

Figure 2-Mode of action of the spray nozzle on the material on the spiral when there is valuable mineral entering the tails port

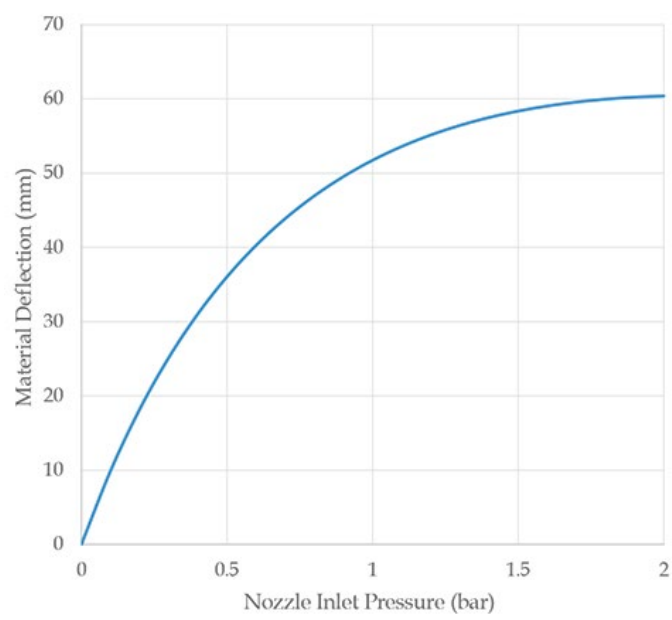

Figure 3-Theoretically achievable deflection versus the nozzle feed water pressure

trajectory of the material on the spiral to deflect it a certain distance from its original path. By varying the amount of deflection, the percentage of material entering a targeted port can be manipulated.

The amount of deflection theoretically achievable in relation to the nozzle feed pressure is shown Figure 3.

The maximum achievable deflection using the selected nozzles and the 2 bar water supply measured on industrial spirals is in the order of $60 \mathrm{~mm}$ (see Figure 3) and is similar to the magnitude of the splitter blade movements resulting from manual changes. Similarly, the resulting mass of material directed away from the concentrate or tails port is similar to that which would be achieved by a manual movement of the product splitter. Therefore, relatively large movements of the mineral band due to process disturbances such as density or feed flow rate fluctuations can be countered through the use of water spray nozzles.

The nozzles appear to be able to run for more than 2 months without requiring maintenance or replacement while using the test site's process water supply.

Laboratory tests show each nozzle requires the equivalent of $2 \mathrm{~L} / \mathrm{min}$ or $2.5 \%$ of the total water on the spiral start for control within the typical variance of grade. This water also assists in

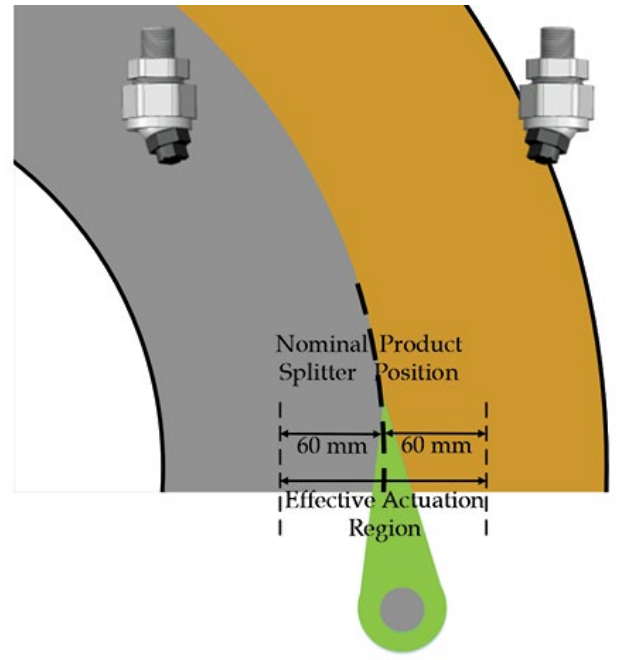

keeping the high-grade material mobile. This water addition can be compensated for by adding less dilution water elsewhere in the spiral circuit.

\section{Integration with an online grade analyser}

The spray nozzle mechanism described here was incorporated into an online control mechanism in combination with an online spectroscopic grade analyser. The analyser provides grade measurements every 15 seconds, which is at a much higher frequency than the concentrate grade variations experienced in practice, thereby providing sufficient closed-loop control performance.

The control system consists of the online grade analyser, a processing unit, a globe control valve, and a water distribution manifold. The opening of the control valve is determined by the difference between the online grade measurements and the applicable set-point. This in turn determines the pressure of the water feeding the spray nozzles, and hence the magnitude of the control action exerted on the spirals. The same control action is applied to all of the spirals in a bank, as it is assumed that differences in the performance of individual spirals can be ignored since they are fed from the same distributor. The schematic layout of the control system is shown in Figure 4. 


\section{Online spiral grade control}

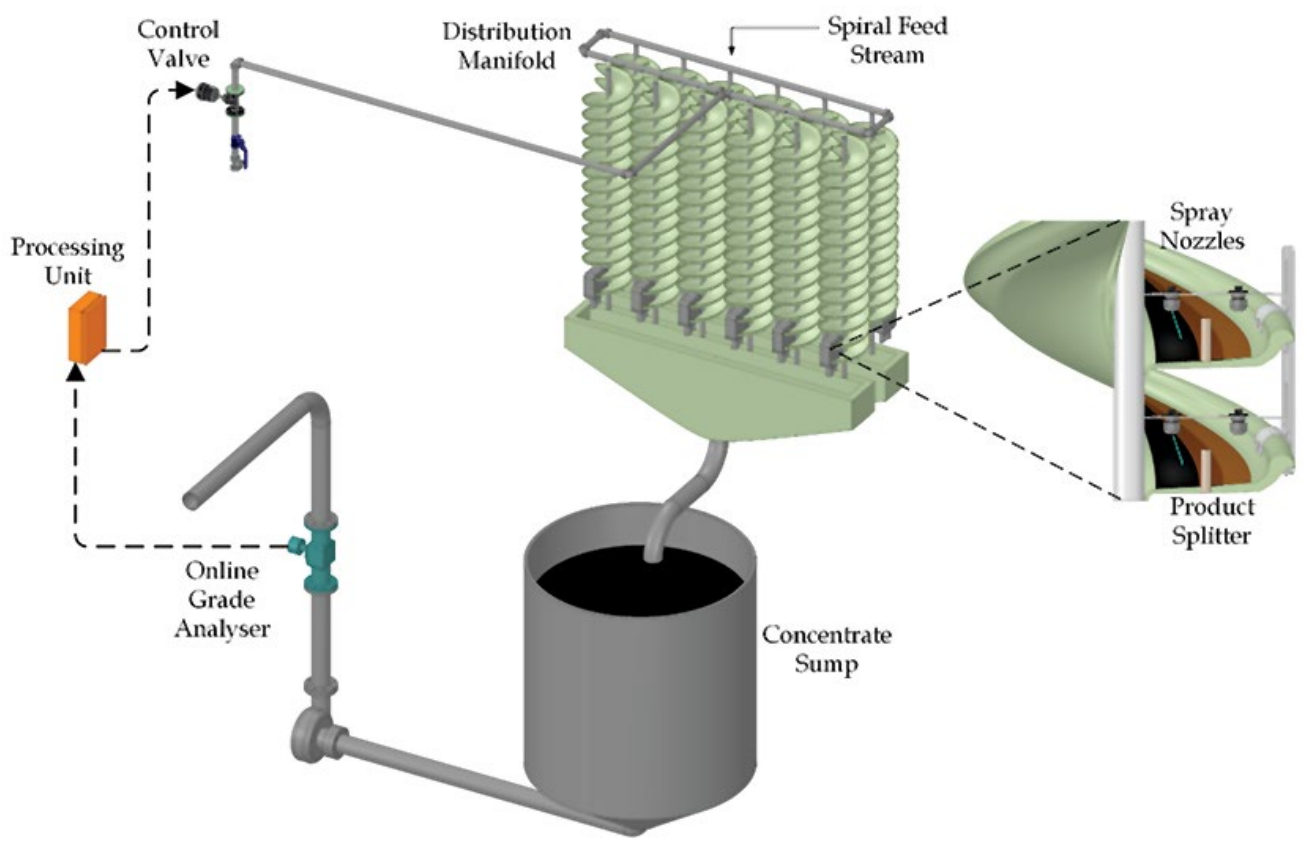

Figure 4-Schematic layout of the spiral grade control system

\section{Experimental}

\section{Industrial test site}

Testing of the control system was carried out on the chrome recovery spiral plant of a UG-2 platinum group metal concentrator on the eastern limb of the Bushveld Complex in South Africa. The spiral plant processes the final flotation tailings for the recovery of chromite. The process flow diagram of the plant is shown in Figure 5. The concentrates from both the mid-recleaner and recleaner banks are combined to form the final concentrate. The grade analyser measures this combined stream.

Under manual control conditions, the plant operators monitor the grade analyser reading and manually adjust the splitter positions of the mid-recleaner bank accordingly, albeit infrequently. This bank was therefore selected for the testing of the automated control system, as its manipulation would most closely resemble the manual control by the operators. Furthermore, this stream constitutes between $60 \%$ and $70 \%$ of the total concentrate mass flow, hence its manipulation will have a significant impact on the final concentrate grade. The midrecleaner bank consists of 12 double-start spiral poles; a total of 24 spirals. Each of these spirals was fitted with a spray nozzle system for the test work.

\section{Spray nozzle effectiveness}

A sampling campaign was conducted to measure the maximum effectiveness of the spray nozzle system on the mid-recleaner bank of spirals. Here, the spray nozzles were activated at maximum control valve opening while crosscut samples of the feed, concentrate, and tails were taken from five separate spirals. These samples were analysed to determine the effects of the spray nozzles on the chromite grade and recovery of the specific spiral bank. This procedure was repeated for the scenario where the spray nozzles direct material towards the concentrate port, and for the scenario where they direct material towards the tails port.

\section{Automated grade control}

The online performance of the control system was evaluated by operating for 160 hours with the grade control system active, with comparisons drawn between the final concentrate grade stability observed under manual control conditions and under automated control conditions respectively. A 24-hour moving average of the concentrate grade was also calculated to represent the grade of the material on the product stockpile.

\section{Operating results and discussion}

\section{The effect of spray nozzles on mineral grade and recovery}

The maximum effectiveness of the spray nozzles when pushing material towards the tails port of the spiral is shown in Figure 6 . Here it can be seen that while a $2.00 \%$ increase in the grade of the concentrate from the mid-recleaner bank was achieved, this was accompanied by a $15.05 \%$ decrease in the recovery of chromite for this bank. Simultaneously, the chromite feed grade to the mid-recleaner bank increased by $2.00 \%$ due to additional chromite-bearing material being pushed towards the tails port, and subsequently recycled back to the mid-recleaner bank via the re-scavenger concentrate. As a result, the upgrade ratio of the mid-recleaner bank remained largely unaffected.

The maximum effectiveness of the spray nozzles when pushing material towards the concentrate port is shown in Figure 7 . Using the maximum control action, an $8.51 \%$ increase in chromite recovery to the concentrate was achieved, accompanied by a $2.33 \%$ decrease in the concentrate chromite grade. Here, the decrease in the concentrate grade was associated with a $1.30 \%$ decrease in the mid-recleaner feed chromite grade due to the reduced amount of chromite-bearing material being collected in the tails product, and thus recycled via the rescavenger concentrate. The net result of this was a decrease in the chromite upgrade ratio of the mid-recleaner bank from 1.11 to 1.06 . 


\section{Online spiral grade control}

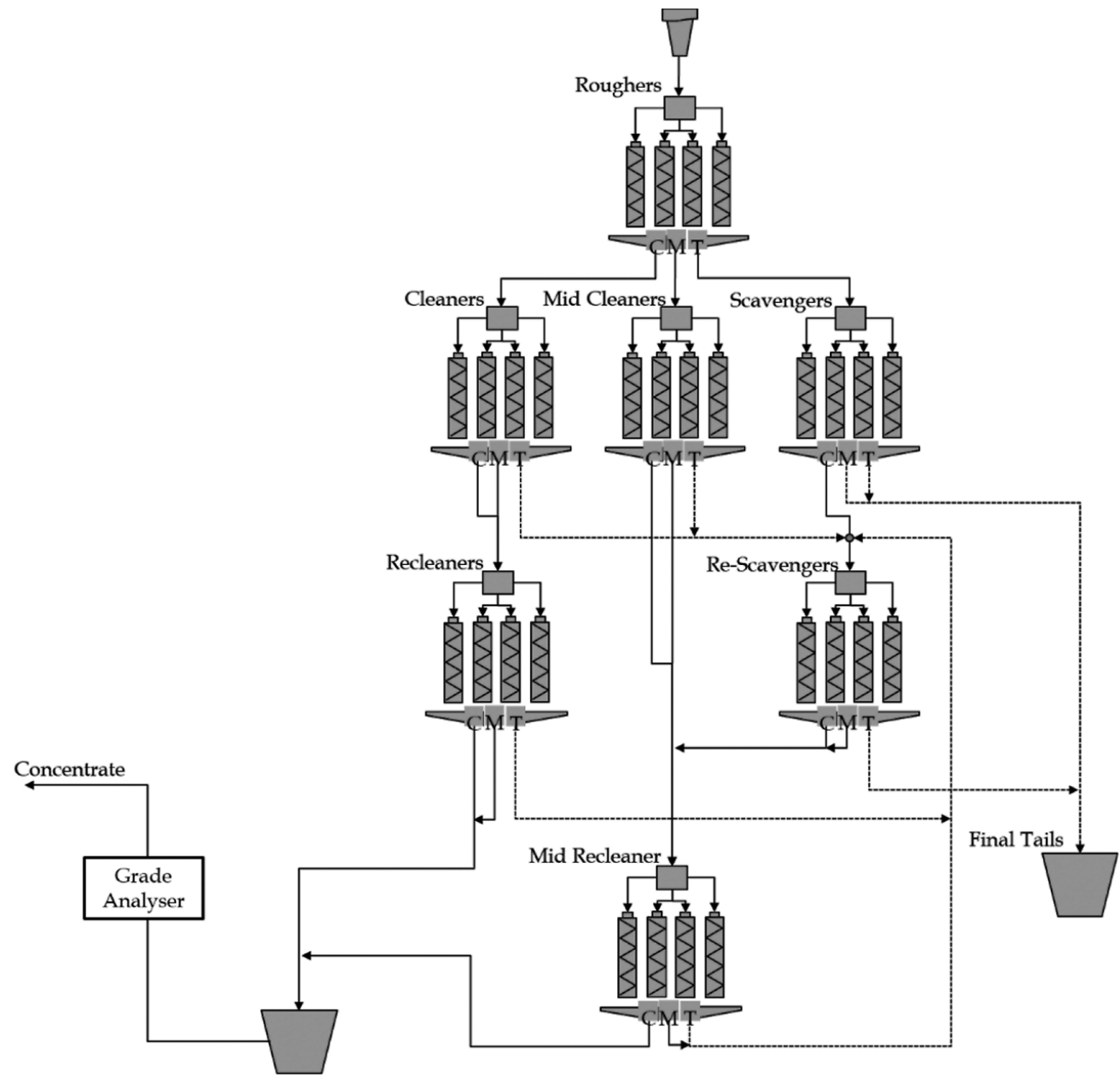

Figure 5-Chromite spiral plant process flow diagram

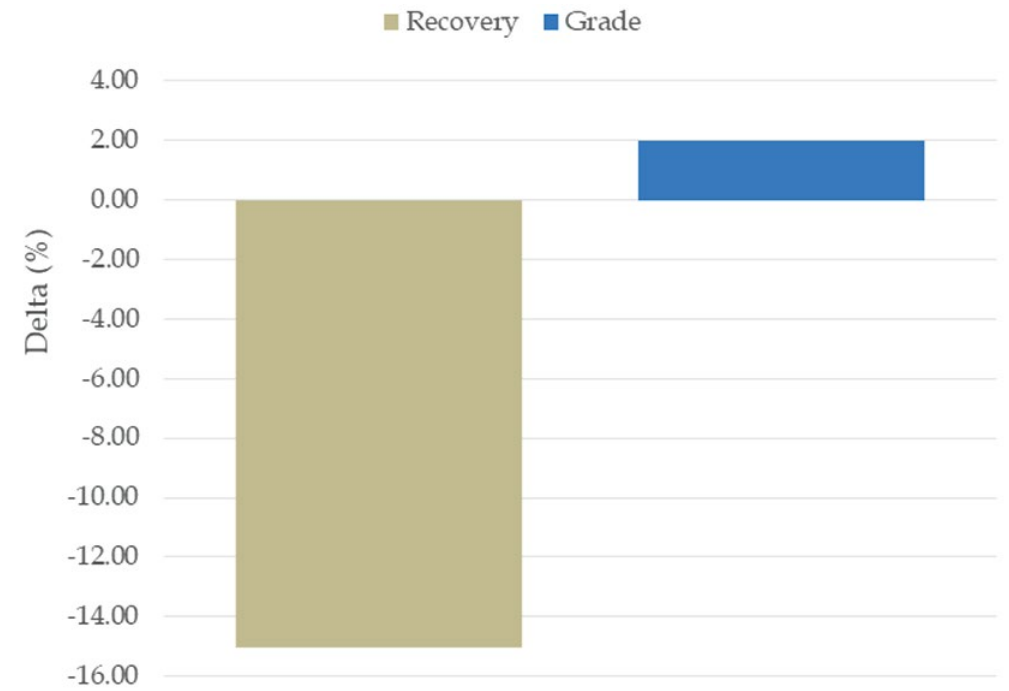

Figure 6-Effect of maximum control action pushing material towards the tails port

While the inverse relationship between the concentrate chromite recovery and chromite grade was to be expected, it is evident that the relationship between these two key variables is nonlinear. The recovery decrease associated with an increase in concentrate grade is significantly greater (1.77 times) than the recovery increase associated with a decrease in concentrate 


\section{Online spiral grade control}

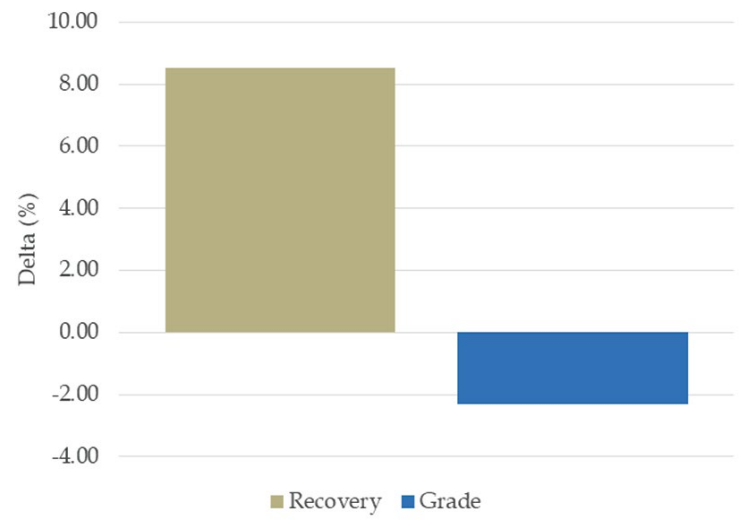

Figure 7-Effect of maximum control action pushing material towards the concentrate port
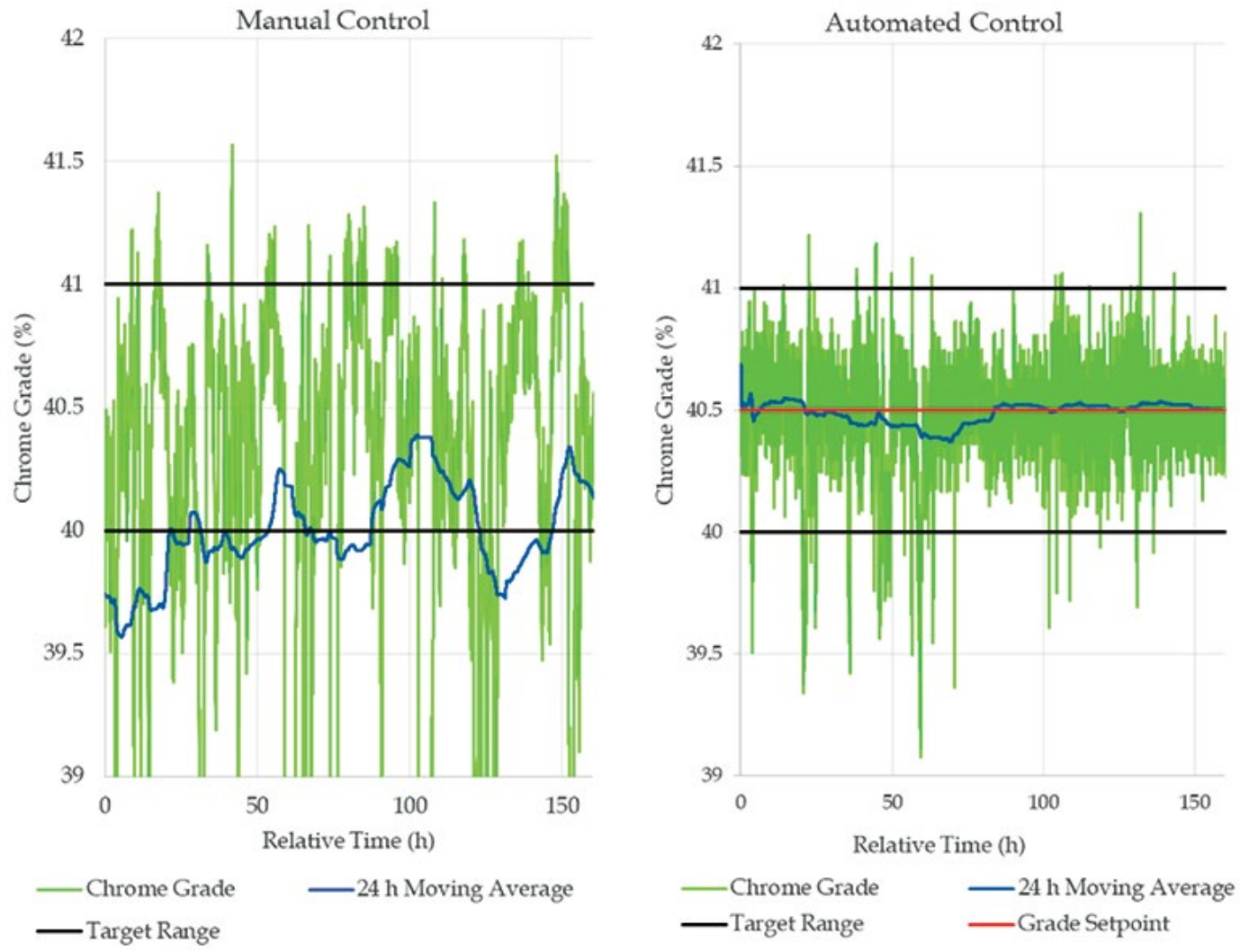

Figure 8-Comparison of the concentrate grade stability under manual and automated control

grade. This relationship is due to the nonlinear, sigmoidal profile of the chromite concentration across the spiral surface. Therefore, a balance between recovery optimization and grade protection should be sought.

\section{Automated concentrate grade control}

Subsequently, an automated grade control test was carried out to determine the effectiveness of the spray nozzles in controlling the final concentrate grade to a set-point. The results of this test are summarized in Figure 8 and Table I.

During the period under manual control, the moving average of the concentrate grade dropped below the minimum grade for the product specification. This indicates that the overall grade of the product on the stockpile was likely to be compromised in these instances.
Conversely, while under automated control, the moving average of the product grade was maintained within $0.15 \%$ of the set-point grade at all times, and well within the product specification limits. The standard deviation of the instantaneous concentrate grade was reduced more than threefold under automated control, while the standard deviation of the 24-hour moving average of the concentrate grade was reduced by more than sixfold, indicating significantly improved concentrate grade stability.

Chromite product specifications normally have a stipulated level for silica content, and therefore the control of the silica grade in the concentrate is also of concern in chromite production. Although control of the silica grade was not a primary objective of this control system, stability in the silica grade was brought about as a consequence of automated chromite grade control. 


\section{Online spiral grade control}

Table I

Summary of the concentrate chromite grade stability under automated and manual control

\begin{tabular}{|l|c|c|}
\hline Measure & Automated control & Manual control \\
\hline Average grade (grade \%) & 40.49 & 40.24 \\
Standard deviation (grade \%) & 0.20 & 0.70 \\
$24 \mathrm{~h}$ average standard deviation (grade \%) & 0.04 & 0.26 \\
\hline
\end{tabular}

Table II

Summary of the concentrate silica grade stability under automated and manual control

\begin{tabular}{|l|c|c|}
\hline Measure & Automated control & Manual control \\
\hline Average silica grade (grade \%) & 3.90 & 3.77 \\
Standard deviation (grade \%) & 0.32 & 0.58 \\
\hline
\end{tabular}

Table II summarizes the silica content variability for the automated and manual control scenarios. The variability of the silica grade during automated control was less than half of that during manual control. By reducing the silica grade variability, the number of instances where the silica grade limits are violated will be reduced, lowering the risk of the product being out of specification.

\section{Production benefits}

A reduction in the variability of the concentrate grade will not significantly impact the productivity of a concentrator in isolation. However, improved stability will allow the safety margin between the targeted concentrate grade and the lower limit for the product specification to be reduced. In doing so, more valuable material can be recovered in the concentrate, thus increasing production and revenue.

For the test site evaluated here it is estimated, based on the UG2 tailings spiral performance characteristics presented by Dawson (2010), that a reduction in the target chromite grade of $0.5 \%$ would yield a $1.2 \%$ increase in chromite recovery to the concentrate. At a sale price of US $\$ 150$ per ton, this would result in a potential increase in revenue of around US\$52 000 per month.

\section{Conclusions}

A water-nozzle control system for gravity spiral concentrators has been developed and tested. Jets of water emanating from spray nozzles mounted above the spiral surface can be used to manipulate the mass flows of material between the ports of the spiral product splitter by displacing the material on the spiral surface about a blast zone. The dimensions of the blast zone can be altered based on the flow rate of the water leaving the spray nozzles, which is a function of the nozzle water pressure. By manipulating the water pressure, the degree of deflection of the material on the spiral surface can be controlled, to a maximum of $60 \mathrm{~mm}$ at a water pressure of 2 bar.

When applied to a chromite recleaner bank of spirals, the water nozzle system was capable of increasing the concentrate chromite grade of that specific bank of spirals by a maximum of $2.00 \%$ with an associated decrease in chromite recovery of $15.05 \%$ when grade protection was targeted. Conversely when chromite recovery protection was targeted, the concentrate chromite grade was decreased by a maximum of $2.33 \%$ with an associated increase in chromite recovery of $8.51 \%$.
The water nozzle system was tested on an industrial site, in conjunction with an online grade analyser, forming a closedloop control system. During the test period, the variability of the measured concentrate grade was decreased significantly, with the standard deviation of the instantaneous concentrate grade being reduced more than threefold compared with the manual control scenario. Furthermore, the standard deviation of the 24 hour moving average concentrate grade was reduced more than sixfold, indicating vastly improved stability of the product quality on the stockpile. In addition, the stability of the silica content of the concentrate was improved, with a twofold reduction in the standard deviation during automated control.

The improved grade stability could allow a plant to reduce the safety margin between the targeted concentrate grade and the lower limit of the product specification, thereby allowing more valuable mineral to be recovered. For this test site, the benefit derived from reducing the concentrate target grade by $0.5 \%$ would result in a recovery improvement of $1.2 \%$, which would yield approximately US\$52 000 per month in additional revenue.

\section{References}

Сооке, G. 2008. An adjustable spiral concentrator. European patent EP20090802279.

DAwson, N.F. 2010. Experiences in the production of metallurgical and chemical UG2 chromite concentrates from PGM tailings streams. Journal of the Southern African Institute of Mining and Metallurgy, vol. 110. pp. 683-690.

GoLD, D. 1991. The investigation and design of a machine vision system for the detection and control of the separation in a spiral ore concentrator. MSc thesis, University of Cape Town, South Africa.

Matthews, B.W., Fletcher, C.A.J., and Partridge, T.C. 1999. Particle flow modelling on spiral concentrators. Proceedings of the Second International Conference on CFD in the Minerals and Process Industries, Melbourne, Australia, 6-8 December 1999. CSIRO Minerals, Melbourne. pp. 211-216.

MishrA, B.K. and TRIPATHY, A. 2010. A preliminary study of particle separation in spiral concentrators using DEM. International Journal of Minerals Processing, vol. 94. pp. 192-195

Mohanty, M.K., WAnG, A.M., and Zhang, B.J. 2014. Automated system for coal spiral. US patent 20140238096 A1.

NiEnAbER, E.C., McCoy, J.T., and AuRET, L. 2017. Spiral concentrator interface monitoring through image processing: A statistical learning approach. IFAC PapersOnLine, no. 50-52. pp. 53-58.

Thornton, C. and CARnell, M. 2018. Practical application of spiral automation technology. Proceedings of the 17th Australian Coal Preparation Conference and Exhibition. Australian Coal Preparation Society, Brisbane. pp. 271-283.

VermaAK, M.K.G., Visser, H.J., Bosman, J.B., and KreBs, G. 2008. A simple process control model for spiral concentrators. Journal of the Southern African Institute of Mining and Metallurgy, vol. 108, no. 3. pp. 147-154.

Welsh, R.A. and Deurbrouk, A.W. 1973. Product separator. US patent 3933249. 